\title{
Article \\ Physical Activity after Colorectal Cancer Diagnosis and Mortality in a Nationwide Retrospective Cohort Study
}

\author{
Meesun Lee ${ }^{1,+}+\mathbb{D}$, Yunseo Lee ${ }^{1,+}$, Doeun Jang ${ }^{2,3}$ and Aesun Shin $2,3,4, *$ (D) \\ 1 Department of Medicine, Seoul National University College of Medicine, Seoul 03080, Korea; \\ gdnoon@snu.ac.kr (M.L.); temari7@naver.com (Y.L.) \\ 2 Department of Preventive Medicine, Seoul National University College of Medicine, Seoul 03080, Korea; \\ doeunj@snu.ac.kr \\ 3 Cancer Research Institute, Seoul National University, Seoul 03080, Korea \\ 4 Integrated Major in Innovative Medical Science, Graduate School of Seoul National University, \\ Seoul 03080, Korea \\ * Correspondence: shinaesun@snu.ac.kr \\ + Authors equally contributed as the first authors of this study.
}

check for updates

Citation: Lee, M.; Lee, Y.; Jang, D.; Shin, A. Physical Activity after Colorectal Cancer Diagnosis and Mortality in a Nationwide Retrospective Cohort Study. Cancers 2021, 13, 4804. https://doi.org/ 10.3390/cancers13194804

Academic Editor: David Wong

Received: 4 August 2021

Accepted: 22 September 2021

Published: 25 September 2021

Publisher's Note: MDPI stays neutral with regard to jurisdictional claims in published maps and institutional affiliations.

Copyright: (C) 2021 by the authors Licensee MDPI, Basel, Switzerland. This article is an open access article distributed under the terms and conditions of the Creative Commons Attribution (CC BY) license (https:// creativecommons.org/licenses/by/ $4.0 /)$.
Simple Summary: Physical activity can help to prevent colorectal cancer, but its importance after cancer diagnosis has not been validated. In this nationwide insurance data-based study of 43,596 colorectal cancer patients, a high level of physical activity after colorectal cancer diagnosis was negatively associated with a risk of death in both colon and rectal cancer patients, particularly in the surgically treated group. Our findings support the importance of the physical activity among colorectal cancer patients.

Abstract: Physical activity reduces the risk of colon cancer, but its prognostic impact after cancer diagnosis remains unclear. To evaluate the association between post-diagnosis activity and causespecific mortality, we reconstructed a colorectal cancer patient cohort from the 2009-16 Korean National Health Insurance Service (NHIS) database. Subgroup analyses were performed by treatment group. In total, 27,143 colon cancer patients and 16,453 rectal cancer patients were included in the analysis (mean follow-up, 4.3 years; median 4.0 years). In the surgically treated group, a high level of activity (the weighted sum of the frequencies for walking, moderate, and vigorous activity greater than or equal to 3 times/week) was inversely associated with all-cause mortality (colon cancer: HR, $0.79 ; 95 \%$ CI, 0.72 to 0.88 ; rectal cancer: $\mathrm{HR}, 0.75 ; 95 \% \mathrm{CI}, 0.66$ to 0.86 ) and colorectal cancer-specific mortality (colon cancer: HR, 0.85; 95\% CI, 0.76 to 0.97 ; rectal cancer: HR, 0.77; 95\% CI, 0.66 to 0.90 ). No significant results were shown for cardiovascular disease-specific mortality. No association was shown in patients who received chemoradiotherapy without surgery. The present study may provide evidence for post-diagnosis physical activity as a prognostic factor in colorectal cancer, particularly in surgically treated early-stage patients.

Keywords: colorectal neoplasms; cancer; physical activity; exercise; survival

\section{Introduction}

Colorectal cancer is the one of the most common cancer types, with an annual incidence of approximately 185 million cases worldwide [1]. In South Korea, it is the second-most common cancer in terms of incidence, with a relative 5 year survival rate of $75.9 \%$ [2].

Among many lifestyle factors, physical activity is a preventive factor for colon cancer [3-6]. Increasing evidence has also shown the role of physical activity in colorectal cancer prognosis. Inverse associations between physical activity and mortality have been suggested across different types of activity, from exercise to leisure time or recreational physical activity, and tumor characteristics including site, stage, and molecular profiles [7-18]. 
However, large-scale population-based studies comprehensively and conjointly considering potential variation by cancer treatment and lifestyle variables are scarce, particularly regarding the East Asian population where the prevalence of insufficient physical activity is higher than the global average [19].

This study assessed the association between post-diagnosis physical activity and overall and cause-specific mortality in a large retrospective cohort of adult colorectal cancer patients between 2009 and 2016 from the Korean National Health Insurance Service (NHIS) database. Additionally, we analyzed the association by causes of death and according to cancer treatment groups to identify patients who could best benefit from physical activity.

\section{Materials and Methods}

\subsection{Database and Patient Selection}

This study was retrospectively conducted based on the NHIS database. The NHIS covers $98 \%$ of the Korean population, and its research database includes information on medical resource utilization, demographic variables, and national health examinations [20].

Colorectal cancer patients were defined as subjects with records for hospitalization with diagnostic codes corresponding to colorectal cancer (ICD-10 code C18-20) as well as treatment such as surgery, radiotherapy, or chemotherapy [21]. Patients with an initial cancer claim from 1 January 2009 to 31 December 2016 were included in the study. The date of cancer diagnosis was defined as the date of the first claim with hospitalization for colorectal cancer. We excluded patients without information on activity before or after diagnosis, with missing life-style variables, who were diagnosed before the age of 20 years, without follow-up, or with concurrent diagnoses of colon and rectal cancers. For cancer site-stratified analysis, the diagnosis with ICD-10 code C18 was classified as colon cancer, and C19-C20 was classified as rectal cancer.

\subsection{Physical Activity Measurement}

Physical activity was measured during the biennial National Health Screening, which included questions on the weekly frequency of vigorous, moderate intensity physical activity and walking performed over a minimal duration of 20 to $30 \mathrm{~min}$. Considering the relative energy expenditure of different activity types, the score for moderate exercise and two times the score for vigorous exercise were added to generate an activity score for individuals aged younger than 65 years. For individuals aged 65 years and older, the scores for moderate exercise and walking were added to two times the score for vigorous exercise. Individuals with a total score greater than or equal to 3 were classified as "high level" exercisers, while the rest were classified as "low level" exercisers. This score was used to reflect the global activity recommendation by the World Health Organization (WHO).

The post-diagnosis physical activity level was extracted from the questionnaire from the first health checkup after cancer diagnosis. Additionally, the pre-diagnosis physical activity was obtained from the closest health checkup before cancer diagnosis.

\subsection{Mortality Follow-Up}

For each patient, follow-up started at the time of post-diagnosis activity measurement and ended at death or the end of the cohort study (31 December 2016). We linked the patient data with death certificates from the Korean National Statistical Office, from which the dates and the specific causes of death were extracted. All-cause mortality was defined as any death with a recorded date. Colorectal cancer-related mortality and cardiovascular disease-related mortality were identified with ICD-10 codes of the cause of death, C18C20 for colorectal cancer, and I20-I25 (coronary heart disease) and I60-I69 (stroke) for cardiovascular diseases.

\subsection{Covariates}

Baseline characteristics were assessed until the post-diagnosis health examination, when physical activity was measured and follow-up period started. Age, sex, and insurance 
premium level (in tertiles, including Medicare recipients in the first tertile) were provided from the insurance claim and the eligibility data at the time of cancer diagnosis. The body mass index (BMI) was calculated from the height and the weight measured during the first post-diagnosis checkup. BMI was categorized as $<18.5 \mathrm{~kg} / \mathrm{m}^{2}, 18.5-22.9 \mathrm{~kg} / \mathrm{m}^{2}$, $23.0-24.9 \mathrm{~kg} / \mathrm{m}^{2}$, and $\geq 25.0 \mathrm{~kg} / \mathrm{m}^{2}$ based on the WHO Asia-Pacific obesity classification [22]. Information on cigarette smoking and alcohol consumption was collected using self-administered questionnaires during the health checkup. Alcohol consumption data were converted into the number of drinks consumed per day and then classified into three groups (nondrinker/social/heavy) in accordance with the U.S. alcohol and alcoholism guidelines [23]. Men were considered to drink heavily if they consumed at least 2 drinks per day on average, and women were considered to drink heavily if they consumed at least 1 drink per day on average. Otherwise, the subjects were considered to drink socially.

The Charlson Comorbidity Index (CCI) was calculated from claims data of at least one hospitalization for specified comorbidities, including cancer, during the year before colorectal cancer diagnosis [24].

Information concerning the cancer stage, which is the most important prognostic factor, was not available from the NHIS database. Instead, we sought to address this issue by stratifying the patients according to the type of cancer treatment they received. The treatment groups were classified into three types: surgery only, surgery with chemotherapy and/or radiotherapy, and chemotherapy with or without radiotherapy.

\subsection{Statistical Analyses}

The distribution of general characteristics was described as $n(\%)$ for colon and rectal cancers separately. Chi-square test was used to compare the characteristics of the activity groups with each cancer. Using the low activity group as a reference, Cox proportional hazards models were used to estimate the HRs and the 95\% CIs of all-cause, colorectal cancer-related, and cardiovascular disease-related mortality. Proportional hazard assumptions were confirmed using log minus log survival plots as well as the Schoenfeld residual method [25]. Stratified analysis was performed according to the treatment group.

The hazards models were adjusted for patient age, sex, BMI, smoking status, level of alcohol consumption, insurance premium, CCI, physical activity before cancer diagnosis, and treatment group. The potential confounding effects of each covariate were tested using Chi-square tests and univariate survival analyses.

For sensitivity analysis, an alternative measurement of physical activity was tested by accounting for the sum of frequencies for moderate-to-vigorous activity instead of the weighted sum.

To exclude the possibility of reverse causality between post-diagnosis physical activity and the health status of the patient, an additional analysis was performed by excluding patients with less than a half-year of follow-up.

A two-sided $p$-value of $<0.05$ was considered statistically significant. All the analyses were performed using SAS version 9.4 and SAS Enterprise Guide (SAS Institute Inc., Cary, NC, USA).

\section{Results}

\subsection{Baseline Characteristics by Physical Activity Category}

In total, 27,143 colon cancer patients and 16,453 rectal cancer patients were identified from the NHIS database after applying the exclusion criteria (Figure 1). A comparison of the demographic and the clinical characteristics of patients before and after selection is shown in Table 1. Briefly, the final study population was younger and more likely to be a male, to be in the lower insurance premium tertiles, or to receive surgery only. 
Patients who had at least 3 insurance claims, were hospitalized, and were treated for colorectal cancer (ICD-10 C18-C20), 2009-2016

$$
(\mathrm{n}=162,320)
$$

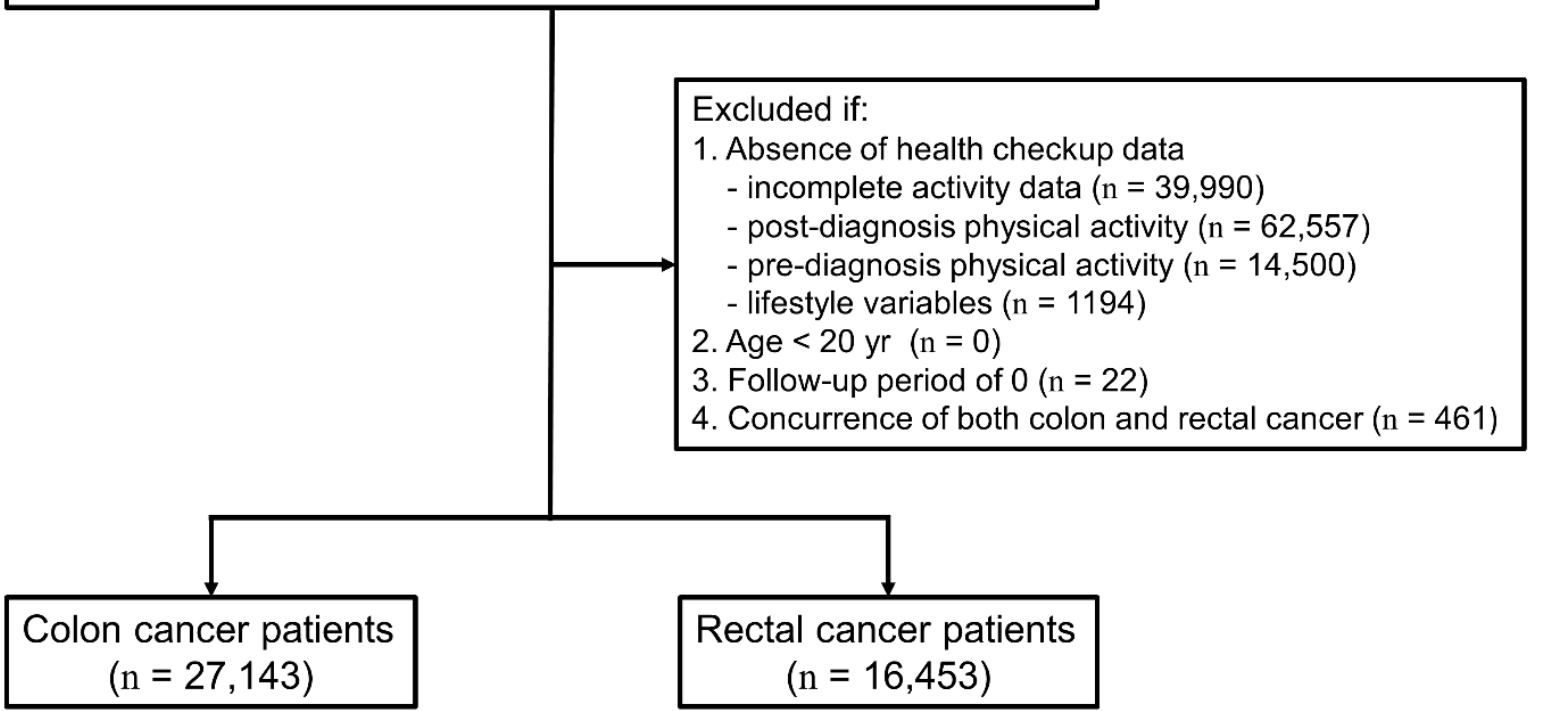

Figure 1. Flow chart to selecting study subjects from the Korean National Health Insurance Service Database. ICD-10 indicates International Classification of Diseases, Tenth Revision.

Table 1. Comparison of the demographic and the clinical characteristics of colorectal cancer patients before and after selection, 2009-2016.

\begin{tabular}{|c|c|c|c|c|c|}
\hline \multirow{3}{*}{ Characteristics } & \multirow{2}{*}{\multicolumn{2}{|c|}{$\begin{array}{c}\text { Before Selection }^{\text {a }} \\
(n=162,320)\end{array}$}} & \multirow{2}{*}{\multicolumn{2}{|c|}{$\begin{array}{c}\text { After Selection }^{b} \\
(n=43,596)\end{array}$}} & \multirow{3}{*}{$p$} \\
\hline & & & & & \\
\hline & $n$ & $\%$ & $n$ & $\%$ & \\
\hline Age, $\geq 60$ years & 107,249 & 66.21 & 27,426 & 62.92 & $<0.01$ \\
\hline missing value ${ }^{\mathrm{c}}$ & 280 & $(0.17)$ & 0 & $(0)$ & \\
\hline Sex & & & & & $<0.01$ \\
\hline male & 97,190 & 59.99 & 27,077 & 62.11 & \\
\hline female & 64,818 & 40.01 & 16,519 & 37.89 & \\
\hline missing value & 312 & $(0.19)$ & 0 & $(0)$ & \\
\hline BMI, $\mathrm{kg} / \mathrm{m}^{2}$ & & & & & 0.01 \\
\hline$<18.5$ & 2020 & 3.37 & 1366 & 3.13 & \\
\hline $18.5-22.9$ & 21,623 & 36.12 & 15,455 & 35.45 & \\
\hline $23.0-24.9$ & 15,616 & 26.09 & 11,504 & 26.39 & \\
\hline$\geq 25.0$ & 20,601 & 34.42 & 15,271 & 35.03 & \\
\hline missing value & 102,460 & $(63.12)$ & 0 & $(0)$ & \\
\hline Smoking & & & & & $<0.01$ \\
\hline never & 35,855 & 59.88 & 26,135 & 59.95 & \\
\hline former & 18,074 & 30.19 & 13,485 & 30.93 & \\
\hline current & 5946 & 9.93 & 3976 & 9.12 & \\
\hline missing value & 102,445 & $(63.11)$ & 0 & $(0)$ & \\
\hline Alcohol consumption & & & & & 0.29 \\
\hline nondrinker & 48,583 & 81.25 & 35,507 & 81.45 & \\
\hline social & 7308 & 12.22 & 5351 & 12.27 & \\
\hline heavy & 3901 & 6.53 & 2738 & 6.28 & \\
\hline missing value & 102,528 & $(63.16)$ & 0 & $(0)$ & \\
\hline
\end{tabular}


Table 1. Cont.

\begin{tabular}{|c|c|c|c|c|c|}
\hline \multirow{3}{*}{ Characteristics } & \multirow{2}{*}{\multicolumn{2}{|c|}{$\begin{array}{c}\text { Before Selection }^{\mathrm{a}} \\
(n=162,320)\end{array}$}} & \multirow{2}{*}{\multicolumn{2}{|c|}{$\begin{array}{c}\text { After Selection }^{b} \\
(n=43,596)\end{array}$}} & \multirow{3}{*}{$p$} \\
\hline & & & & & \\
\hline & $n$ & $\%$ & $n$ & $\%$ & \\
\hline Insurance premium & & & & & $<0.01$ \\
\hline 1st tertile & 34,653 & 22.95 & 11,080 & 25.41 & \\
\hline 2nd tertile & 43,254 & 28.65 & 12,232 & 28.06 & \\
\hline 3rd tertile & 73,063 & 48.40 & 20,284 & 46.53 & \\
\hline missing value & 11,350 & $(6.99)$ & 0 & $(0)$ & \\
\hline Pre-diagnosis PA & & & & & 0.39 \\
\hline low & 51,654 & 47.96 & 20,804 & 47.72 & \\
\hline high & 56,043 & 52.04 & 22,792 & 52.28 & \\
\hline missing value & 54,623 & $(33.65)$ & 0 & $(0)$ & \\
\hline Post-diagnosis PA & & & & & $<0.01$ \\
\hline low & 25,376 & 42.46 & 17,892 & 41.04 & \\
\hline high & 34,383 & 57.54 & 25,704 & 58.96 & \\
\hline missing value & 102,561 & $(63.18)$ & 0 & $(0)$ & \\
\hline Treatment & & & & & $<0.01$ \\
\hline surgery only & 89,570 & 57.30 & 30,224 & 69.33 & \\
\hline $\begin{array}{c}\text { surgery with chemotherapy and/or } \\
\text { radiotherapy }\end{array}$ & 56,245 & 35.98 & 12,687 & 29.10 & \\
\hline $\begin{array}{c}\text { chemotherapy with or without } \\
\text { radiotherapy }\end{array}$ & 10,494 & 6.72 & 685 & 1.57 & \\
\hline missing value & 6011 & $(3.70)$ & 0 & $(0)$ & \\
\hline
\end{tabular}

Abbreviations: PA, physical activity; $n$, number of patients; BMI, body mass index. ${ }^{\text {a }}$ Colorectal cancer patients who were collected as the initial study subjects from the Korean National Health Insurance Service Database before applying the exclusion criteria (absence of health checkup data, under the age of 20 years, follow-up period of 0 , concurrence of both colon and rectal cancer). ${ }^{b}$ Colorectal cancer patients who were selected as the final study subjects after applying the exclusion criteria. ${ }^{\mathrm{c}}$ The percentage in parentheses is the fraction of missing values for each variable.

Their baseline characteristics were assessed from the closest health checkup before diagnosis until the first health checkup after diagnosis. The mean age at the time of cancer diagnosis was 62.7 years (standard deviation, 10.4 years). The patients were followed for a mean duration of 4.3 years (median, 4.0 years). The physical activity level was assessed at an average of 1.8 years after cancer diagnosis.

The baseline characteristics of the colorectal cancer patients are shown according to the cancer location and the physical activity categories (Table 2). In both colon and rectal cancers, physically active patients were significantly older, had a greater male proportion, were less underweight or obese, had a smaller ratio of current smokers and heavy drinkers, had greater income levels, had a higher pre-diagnosis activity level, and included a lower proportion of patients treated with chemotherapy with or without radiotherapy. The distribution of the CCI was not significantly different. For both cancers, the most common treatment was surgery without additional radiotherapy or chemotherapy, which was performed on $74.5 \%$ of colon cancer patients and $60.7 \%$ of rectal cancer patients. Fewer than $2 \%$ of the patients had no record of surgical resection but received chemotherapy with or without radiotherapy. 
Table 2. Demographic and clinical characteristics of colorectal cancer patients by post-diagnosis physical activity levels, 2009-2016.

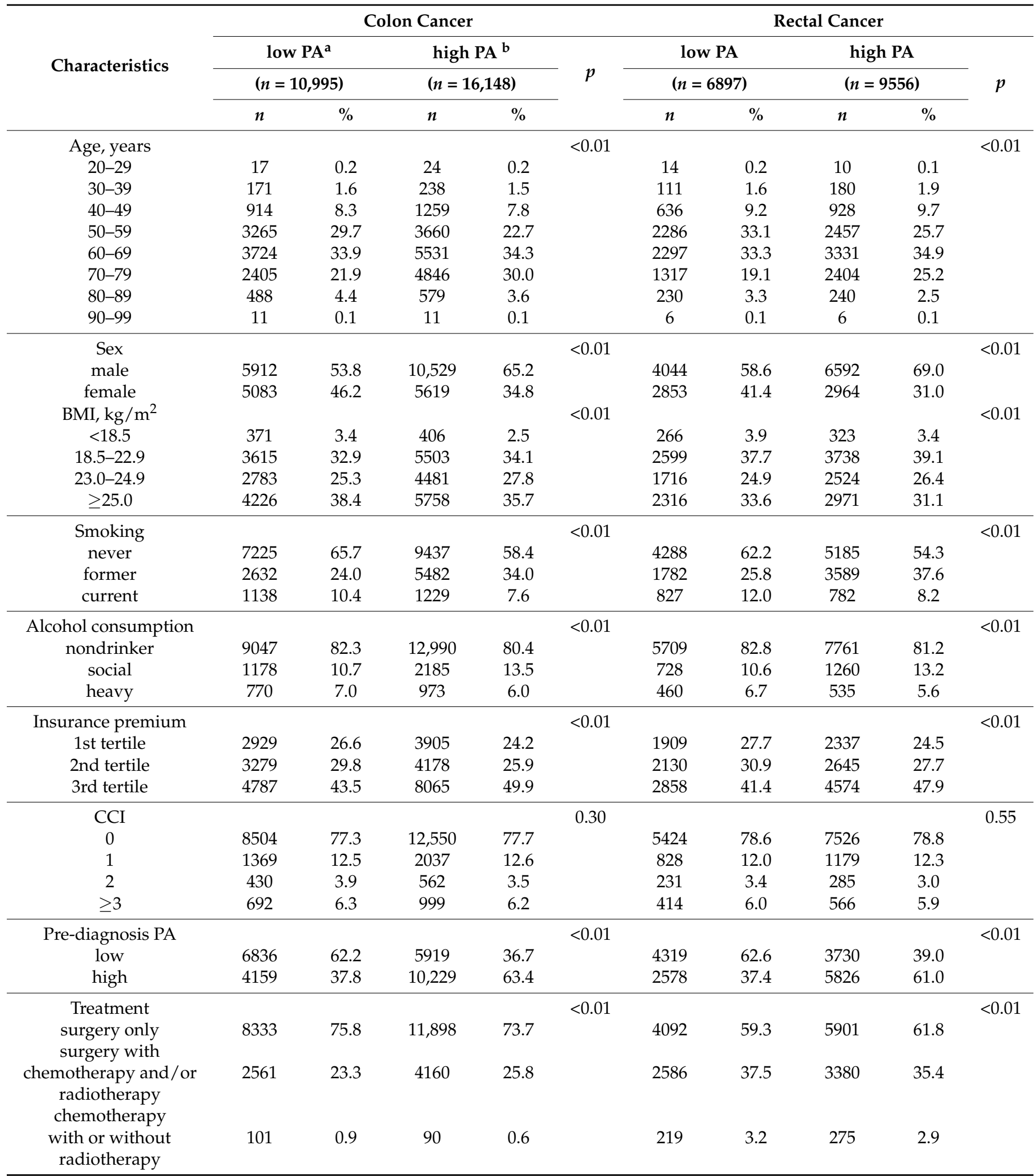

Abbreviations: PA, physical activity; $n$, number of patients; BMI, body mass index; CCI, Charlson comorbidity index. ${ }^{\text {a }}$ Patients with a low level of activity (the weighted sum of the frequencies for walking, moderate, and vigorous activity fewer than three times/week).

$\mathrm{b}$ Patients with a high level of activity (the weighted sum of the frequencies for walking, moderate, and vigorous activity greater than or equal to three times/week). 


\subsection{Physical Activity and All-Cause, Colorectal Cancer, and Cardiovascular Mortality}

During 106,927 person-years of follow up, 1673 deaths by colon cancer patients and 971 deaths by rectal cancer patients were observed. Among them, $69.6 \%$ of the deaths were due to colorectal cancer, and 3.0\% were due to other causes including cardiovascular diseases such as coronary heart diseases (International Classification of Diseases, Tenth Revision (ICD-10) code I20-I25) or stroke (ICD-10 code I60-I69). After adjustment, both colon and rectal cancer patients with a high level of activity showed lower all-cause mortality (colon cancer: hazard ratio (HR), $0.79 ; 95 \%$ confidence interval $(95 \% \mathrm{CI}), 0.72$ to 0.88 ; rectal cancer: HR, 0.75 ; $95 \%$ CI, 0.66 to 0.86 ) (Table 2; Figure 2). A high level of activity was similarly associated with a lowered risk of colorectal cancer-specific mortality (colon cancer: HR, 0.85 ; 95\% CI, 0.76 to 0.97 ; rectal cancer: HR, $0.77 ; 95 \%$ CI, 0.66 to 0.90 ) (Table 3). However, no significant association was found between cardiovascular disease-related deaths and physical activity (colon cancer: HR, $0.87 ; 95 \% \mathrm{CI}, 0.49$ to 1.54 ; rectal cancer: HR, $0.88,95 \%$ CI 0.40 to 1.94 ) (Table 3). Additionally, sensitivity analysis for physical activity was performed by considering only the sum of the frequency of moderate-to-vigorous activity. Again, all-cause mortality and colorectal cancer-related mortality were lower in the physically active patients but not cardiovascular disease-related mortality (Supplementary Table S1).

Table 3. Post-diagnosis physical activity and all-cause/colorectal cancer/cardiovascular mortality in colon and rectal cancer patients.

\begin{tabular}{|c|c|c|c|c|c|c|c|c|c|c|c|c|}
\hline \multirow{2}{*}{ Treatment } & \multirow{2}{*}{ PA } & \multirow{2}{*}{$n$} & \multirow{2}{*}{$\begin{array}{l}\text { Person- } \\
\text { Years }\end{array}$} & \multicolumn{2}{|c|}{ All-Cause } & \multirow[b]{2}{*}{$(95 \% \mathrm{CI})$} & \multicolumn{2}{|c|}{ Colorectal Cancer } & \multicolumn{4}{|c|}{ Cardiovascular } \\
\hline & & & & Events & HR & & Events & HR & $(95 \% \mathrm{CI})$ & Events & HR & $(95 \% \mathrm{CI})$ \\
\hline \multicolumn{13}{|l|}{ Colon cancer } \\
\hline \multirow{3}{*}{ Total } & & 27,143 & $66,458.54$ & 1673 & & & 1155 & & & 51 & & \\
\hline & Low $^{a}$ & 10,995 & $26,780.26$ & 734 & 1 (Ref) & & 488 & 1 (Ref) & & 23 & 1 (Ref) & \\
\hline & High $^{b}$ & 16,148 & $39,678.27$ & 939 & 0.79 & $(0.72,0.88)$ & 667 & 0.85 & $(0.76,0.97)$ & 28 & 0.87 & $\begin{array}{l}(0.49 \\
1.54)\end{array}$ \\
\hline \multirow{3}{*}{ Surgery only } & & 20,231 & $51,613.34$ & 754 & & & 380 & & & 44 & & \\
\hline & low & 8333 & $21,148.54$ & 352 & 1 (Ref) & & 172 & 1 (Ref) & & 20 & 1 (Ref) & \\
\hline & high & 11,898 & $30,464.80$ & 402 & 0.75 & $(0.65,0.87)$ & 208 & 0.81 & $(0.66,1.00)$ & 24 & 0.86 & $\begin{array}{l}(0.46, \\
1.59)\end{array}$ \\
\hline \multirow{3}{*}{$\begin{array}{l}\text { Surgery with } \\
\text { chemotherapy } \\
\text { and/or } \\
\text { radiotherapy }\end{array}$} & & 6721 & $14,495.30$ & 841 & & & 703 & & & 7 & & \\
\hline & low & 2561 & 5454.82 & 341 & 1 (Ref) & & 278 & 1 (Ref) & & 3 & 1 (Ref) & \\
\hline & high & 4160 & 9040.48 & 500 & 0.84 & $(0.73,0.97)$ & 425 & 0.89 & $(0.76,1.04)$ & 4 & 0.92 & $\begin{array}{l}(0.20, \\
4.28)\end{array}$ \\
\hline Chemotherapy & & 191 & 349.90 & 78 & & & 72 & & & 0 & & \\
\hline with or without & low & 101 & 176.91 & 41 & 1 (Ref) & & 38 & 1 (Ref) & & 0 & & \\
\hline radiotherapy & high & 90 & 172.99 & 37 & 0.74 & $(0.46,1.19)$ & 34 & 0.70 & $(0.43,1.16)$ & 0 & & \\
\hline \multicolumn{13}{|l|}{ Rectal cancer } \\
\hline \multirow{3}{*}{ Total } & & 16,453 & $40,468.54$ & 971 & & & 686 & & & 27 & & \\
\hline & low & 6897 & $16,730.29$ & 463 & 1 (Ref) & & 328 & 1 (Ref) & & 11 & 1 (Ref) & \\
\hline & high & 9556 & $23,738.25$ & 508 & 0.75 & $(0.66,0.86)$ & 358 & 0.77 & $(0.66,0.90)$ & 16 & 0.88 & $\begin{array}{l}(0.40, \\
1.94)\end{array}$ \\
\hline \multirow{3}{*}{ Surgery only } & & 9993 & $26,008.18$ & 318 & & & 148 & & & 19 & & \\
\hline & low & 4092 & $10,566.05$ & 149 & 1 (Ref) & & 74 & 1 (Ref) & & 7 & 1 (Ref) & \\
\hline & high & 5901 & $15,442.12$ & 169 & 0.75 & $(0.60,0.95)$ & 74 & 0.69 & $(0.49,0.96)$ & 12 & 1.00 & $\begin{array}{l}(0.38, \\
2.63)\end{array}$ \\
\hline \multirow{3}{*}{$\begin{array}{l}\text { Surgery with } \\
\text { chemotherapy } \\
\text { and/or } \\
\text { radiotherapy }\end{array}$} & & 5966 & $13,666.00$ & 552 & & & 447 & & & 8 & & \\
\hline & low & 2586 & 5845.20 & 262 & 1 (Ref) & & 207 & 1 (Ref) & & 4 & 1 (Ref) & \\
\hline & high & 3380 & 7820.80 & 290 & 0.81 & $(0.68,0.96)$ & 240 & 0.86 & $(0.71,1.04)$ & 4 & 0.73 & $\begin{array}{l}(0.17, \\
3.05)\end{array}$ \\
\hline \multirow{3}{*}{$\begin{array}{l}\text { Chemotherapy } \\
\text { with or without } \\
\text { radiotherapy }\end{array}$} & & 494 & 794.36 & 101 & & & 91 & & & 0 & & \\
\hline & low & 219 & 319.03 & 52 & 1 (Ref) & & 47 & 1 (Ref) & & 0 & & \\
\hline & high & 275 & 475.33 & 49 & 0.72 & $(0.46,1.11)$ & 44 & 0.71 & $(0.45,1.12)$ & 0 & & \\
\hline
\end{tabular}

Adjusted for age at diagnosis, sex, BMI, smoking, alcohol consumption, insurance premium, Charlson comorbidity index, pre-diagnosis physical activity. For all patients, treatment options were also adjusted. Abbreviations: PA, physical activity; $n$, number of patients; HR, hazard ratio; 95\% CI, 95\% confidence interval; Ref, reference. ${ }^{\text {a }}$ Patients with a low level of activity (the weighted sum of the frequencies for walking, moderate, and vigorous activity fewer than three times/week). ${ }^{b}$ Patients with a high level of activity (the weighted sum of the frequencies for walking, moderate, and vigorous activity greater than or equal to three times/week). 
a
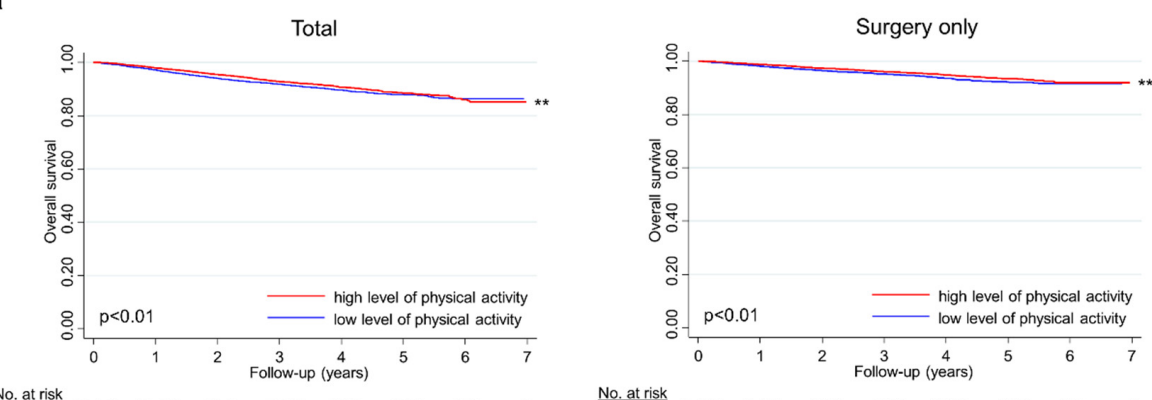

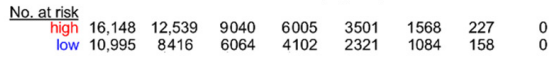
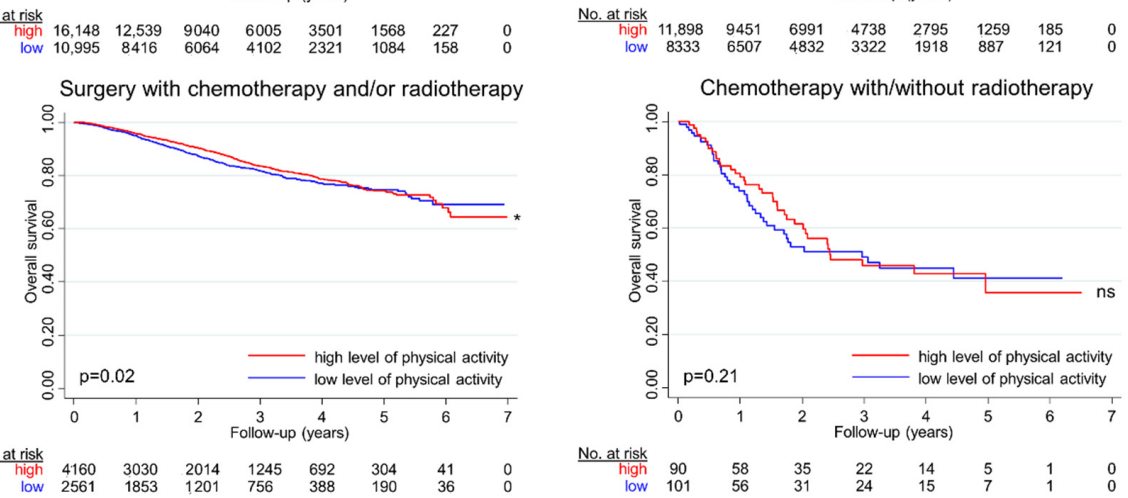

b
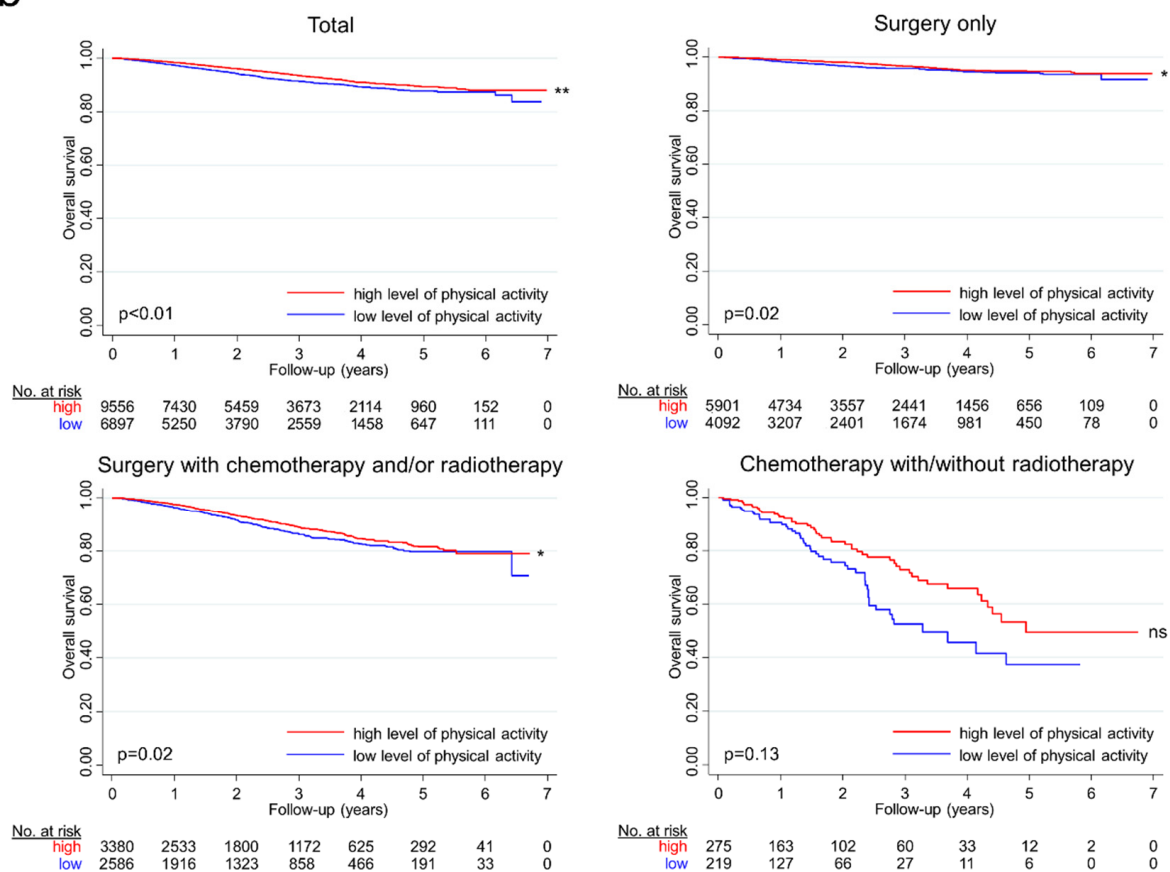

Figure 2. Kaplan-Meier survival curves as stratified by physical activity groups for colon and rectal cancer. Kaplan-Meier survival curves for colon cancer patients (a) and rectal cancer patients (b), stratified by the following treatment groups: total, surgery only, surgery with chemotherapy and/or radiotherapy, and chemotherapy with or without radiotherapy. The red line represents the survival probability of patients with a high level of activity (the weighted sum of the frequencies for walking, moderate, and vigorous activity greater than or equal to three times/week), and the blue line represents the survival probability of patients with a low level of activity. ${ }^{* *}, *$, and ns next to graphs indicate $p$-values lower than $0.01, p$-values lower than 0.05 , and nonsignificant results, respectively. The results indicate that satisfying the recommended level of activity is associated with a lowered risk of mortality in colorectal cancer patients, particularly in patients who received surgery with or without other treatment options such as chemotherapy or radiotherapy. 
The difference in mortality could also be due to reverse causation such as premorbid or elderly patients only having a limited amount of physical capacity. This possibility was explored by excluding patients who died within 6 months of follow-up. Even after excluding them, the association between physical activity and overall mortality was still significant (colon cancer: HR, 0.82; 95\% CI, 0.73 to 0.91 ; rectal cancer: HR, 0.79; 95\% CI, 0.69 to 0.91 ). The association was also consistent in patients aged 65 years or older (colon cancer: $\mathrm{HR}, 0.76$; $95 \% \mathrm{CI}, 0.67$ to 0.86 ; rectal cancer: $\mathrm{HR}, 0.76$; $95 \% \mathrm{CI}, 0.64$ to 0.90 ).

Analysis of the effect of pre-diagnostic physical activity on colorectal cancer prognosis revealed that satisfying the activity recommendation during the pre-diagnosis period was associated with significantly lower all-cause, colorectal cancer-related, and cardiovascular disease-related mortality among colon cancer patients. In rectal cancer, however, the association was only significant for all-cause mortality (Supplementary Table S2). The results of the analyses for the change between pre- and post-diagnostic physical activity were conflicting, but a decrease in physical activity after cancer diagnosis was consistently associated with higher mortality in both colon and rectal cancer patients (Supplementary Table S3).

\subsection{Physical Activity and Colorectal Cancer Treatment}

In the stratified analysis by cancer treatment, active patients who only received surgical resection had an adjusted hazard ratio of 0.75 (95\% CI, 0.65 to 0.87 ), and those who received surgery as well as chemotherapy and/or radiotherapy had an adjusted hazard ratio of 0.84 with a high level of activity (95\% CI, 0.73 to 0.97$)$ for colon cancer. However, physical activity was not significantly associated with mortality in those who did not receive surgery but received chemotherapy with or without radiotherapy. Likewise, in rectal cancer patients, physical activity was associated with lower mortality in surgically treated patients but not in the nonsurgically treated patients (Table 3; Figure 2).

\section{Discussion}

Our analyses uncovered an inverse association between post-diagnosis physical activity and mortality in both colon and rectal cancer patients. This finding implies that physical activity, apart from being an independent protective factor against colorectal cancer, may also serve as a prognostic determinant of colorectal cancer. Additionally, our results suggest that activity may be most beneficial in surgically treatable patients, who are presumably early-stage cancer patients with longer survival times after cancer treatment.

The benefits of physical activity may have resulted from changing the biological processes related to cancer progression. Physical activity was suggested to affect tumor metabolism in the acute phase and then induce immunological control of tumor growth in the long term [26]. The Akt/mTOR signaling pathway, a mechanism potentially related to colorectal cancer growth and metastasis, was shown to be differentially regulated during exercise $[27,28]$. Inflammatory markers such as TNF- $\alpha$ and IL- 6 decreased after exercise training in a study of breast cancer survivors [29]. A mouse model study also suggested that natural killer cells were mobilized during exercise [30]. The accumulation of these effects could have led to better survival of the active patients.

Additionally, physical activity may be crucial in the quality of life of patients. Active cancer patients are generally shown to experience better cardiovascular recovery during treatment [31]. They also have less cancer-related fatigue and fewer side effects such as treatment-induced anemia [32,33]. In accordance with these results, the amount of anxiety or depression is lower in patients with higher amounts of physical activity [34]. Combined with our results, these studies provide evidence that physical activity may be crucial for both the quantity and the quality of life. However, this interpretation requires further evaluation, because previous studies primarily focused on the effects of exercise, which only included voluntary and regular body movements and not all types of physical activity.

The similarity of results for colon and rectal cancer patients should be noted, because the role of physical activity in cancer prevention is established for only colon cancer [35]. 
These cancers differ not only in their anatomical origin but also in several important clinical features. The role of radiotherapy is limited in colon cancer treatment, but the effect of adjuvant systemic treatment on survival is more evident against this cancer. The most common metastatic site of colorectal cancers is the liver, but rectal cancer may also initially metastasize to the lungs because of its drainage into the inferior vena cava rather than the portal venous system [36]. Our study suggests evidence that, despite these differences, physical activity acts as a common prognostic factor in these cancers.

In our study, patients who did not receive surgery received no benefit from high levels of activity. An explanation for this result is that the stages of cancer in this group were too far advanced to be moderated by physical activity. Another possibility is that these patients had more comorbidities that overwhelmed the benefits of physical activity. However, the results remained unchanged even after adjusting for the CCI. Finally, surveillance or treatment for other primary cancers, recorded in $10 \%$ of colorectal cancer patients, could have added heterogeneity to the data. When we omitted patients with at least one record of other cancers (identified by the ICD-10 " $\mathrm{C}$ " code) within three years before the colorectal cancer diagnosis, the association between activity and mortality in nonsurgically treated patients was significant for colon cancer but not rectal cancer (colon cancer: HR, 0.72; 95\% CI, 0.42 to 0.98 ; rectal cancer: $\mathrm{HR}, 0.75$; $95 \% \mathrm{CI}, 0.45$ to 1.17 ). Careful interpretation is required because of the small number of patients treated without surgery [37]. However, although other studies suggested a significant reduction in mortality in advanced but active cancer patients [38-40], our results suggest that exercise rehabilitation may be most beneficial during earlier stages of cancer in which medical treatments such as surgery, chemotherapy, or radiotherapy are all available.

Despite the decrease in all-cause mortality as well as colorectal cancer-related mortality, we did not observe a decrease in cardiovascular disease-related mortality, in contrast to results from the previous literature [41]. The reason may be due to the insufficiency of follow-up to capture the slow development of cardiovascular events, because we observed $3 \%$ of deaths from cardiovascular diseases, whereas $10 \%$ to $20 \%$ of deaths were reported from other study of cancer patients [42]. Another possibility is that the noncancer death profiles are truly unaffected by activity in the cancer patients. Additional studies with longer follow-up could provide further insight into how the causes of death in colorectal cancer patients change according to activity level.

One of the strengths of this study relates to the large size of the cohort. A meta-analysis on the relationship between post-diagnosis physical activity and colorectal cancer showed that the number of total subjects in previous studies was in the hundreds to thousands [43]. By contrast, our results clarified the relationship between activity and mortality in a larger cohort that was representative of the national population and included more than 40,000 patients. Furthermore, the use of Korean NHIS data allowed us to evaluate the effect of physical activity on the Asian population, a phenomenon that was not sufficiently studied previously.

Additionally, the large size of the cohort enabled us to perform stratified analyses on cancer sites and treatment options without decreasing the reliability of the statistical results. Cancer site-stratification was used to distinguish among the results from colon and rectal cancers. The treatment options were used as indicators of the cancer stage, the primary prognostic factor of colorectal cancer that was not directly available from our data. These stratifications made it possible to demonstrate the adjuvant effect of physical activity in detail, the finding of which could be meaningful during clinical applications of the data.

There are several limitations that must be considered. First, selection bias may occur during study subject selection because many colorectal patients were excluded because of the absent or the incomplete post-diagnosis health checkups. The largest difference was shown in the distribution of treatment options, likely because of the short survival in patients with advanced cancer (Table 1). Although no differences were found in the proportion of the social/heavy alcohol drinkers between total and final study populations, the final study population showed a slightly higher proportion of former smokers and 
high pre- and post-diagnostic PA levels. The study population may have a more desirable lifestyle than the excluded patients, and it is unlikely that the internal validity for comparing PA groups was affected.

Second, the retrospective design of the study made it challenging to incorporate residual confounding factors such as performance status and validate the causality between mortality and different factors that were included in the analyses. The level of physical activity may only reflect health status but may not be a determinant of health status. To counter this interpretation, we adjusted our model for diverse prognostic factors of colorectal cancer and performed sensitivity analysis to confirm our results. An analysis with residual confounding factors and time-varying covariates can further strengthen the data. Third, our data only included information on the minimal duration and intensity of physical activity. This approach precluded the evaluation of activities in the standard measurement of MET minutes per week or the analysis on the dose effect of the activity. When we validated our activity criteria by comparing the achievement rates using the national cancer statistics, the proportion of active patients was larger in our study than the national average of $57.1 \%$, suggesting that our criteria might have been more relaxed [44]. However, our finding could also be explained by a greater interest in activity among colorectal cancer patients, and analyses using an alternative definition of activity showed a similar relationship to survival. Fourth, a relatively long interval existed between cancer diagnosis and health checkup (average, 1.8 years; standard deviation, 1.2 years), possibly leading to a bias toward patients with relatively better survival sufficient to attend health checkups. Finally, the bias due to competing risk between the causes of death cannot be completely excluded.

\section{Conclusions}

A high level of post-diagnosis physical activity was associated with lower mortality in surgically treated colorectal patients, considering the variation by cancer treatment and lifestyle factors. Future research is necessary to consider the interaction among activity, performance status, and cancer stage and to understand the underlying molecular mechanisms supporting the clinical role of post-diagnosis activity.

Supplementary Materials: The following are available online at https: / www.mdpi.com/article / 10.3390 / cancers13194804/s1, Table S1: Weekly frequency of moderate-to-vigorous post-diagnosis physical activity and all-cause/colorectal cancer/cardiovascular mortality in colon and rectal cancer patients, Table S2: Pre-diagnosis physical activity and all-cause/colorectal cancer/cardiovascular mortality in colon and rectal cancer patients, Table S3: Change of physical activity levels before and after diagnosis and all-cause/colorectal cancer/cardiovascular mortality in colon and rectal cancer patients.

Author Contributions: Conceptualization, M.L., Y.L. and A.S.; Data Curation, M.L., Y.L., D.J. and A.S.; Formal Analysis, M.L., Y.L., D.J. and A.S.; Writing-Original Draft Preparation, M.L. and Y.L.; Writing-Review and Editing, M.L., Y.L. and A.S.; Supervision, A.S.; Funding Acquisition, A.S. All authors have read and agreed to the published version of the manuscript.

Funding: This research was funded by the National Research Foundation of Korea (2017R1A2B4009233) and the SNU Undergraduate Research Program through the Faculty of Liberal Education, Seoul National University (2019).

Institutional Review Board Statement: The study was conducted according to the guidelines of the Declaration of Helsinki and approved by the Institutional Review Board of Seoul National University College of Medicine/Seoul National University Hospital (IRB no. E-1906-116-1041).

Informed Consent Statement: Patient consent was waived because of the anonymized structure of the National Health Insurance Service (NHIS) research database provided for the study.

Data Availability Statement: To protect potentially identifiable information on subjects, ethical approval is required to access data. The data are available from the Korean NHIS database for researchers who meet the criteria for access. 
Conflicts of Interest: The authors declare no conflict of interest.

\section{References}

1. Bray, F.; Ferlay, J.; Soerjomataram, I.; Siegel, R.L.; Torre, L.A.; Jemal, A. Global cancer statistics 2018: GLOBOCAN estimates of incidence and mortality worldwide for 36 cancers in 185 countries. CA Cancer J. Clin. 2018, 68, 394-424. [CrossRef]

2. Jung, K.W.; Won, Y.J.; Kong, H.J.; Lee, E.S. Cancer Statistics in Korea: Incidence, Mortality, Survival, and Prevalence in 2016. Cancer Res. Treat. 2019, 51, 417-430. [CrossRef]

3. Clinton, S.K.; Giovannucci, E.L.; Hursting, S.D. The World Cancer Research Fund/American Institute for Cancer Research Third Expert Report on Diet, Nutrition, Physical Activity, and Cancer: Impact and Future Directions. J. Nutr. 2020, 150, 663-671. [CrossRef]

4. Giovannucci, E.; Ascherio, A.; Rimm, E.B.; Colditz, G.A.; Stampfer, M.J.; Willett, W.C. Physical activity, obesity, and risk for colon cancer and adenoma in men. Ann. Intern. Med. 1995, 122, 327-334. [CrossRef]

5. Samad, A.K.; Taylor, R.S.; Marshall, T.; Chapman, M.A. A meta-analysis of the association of physical activity with reduced risk of colorectal cancer. Colorectal. Dis. 2005, 7, 204-213. [CrossRef]

6. Thune, I.; Furberg, A.S. Physical activity and cancer risk: Dose-response and cancer, all sites and site-specific. Med. Sci. Sports Exerc. 2001, 33, S530-S550; discussion S609-S510. [CrossRef] [PubMed]

7. Arem, H.; Pfeiffer, R.M.; Engels, E.A.; Alfano, C.M.; Hollenbeck, A.; Park, Y.; Matthews, C.E. Pre- and postdiagnosis physical activity, television viewing, and mortality among patients with colorectal cancer in the National Institutes of Health-AARP Diet and Health Study. J. Clin. Oncol. 2015, 33, 180-188. [CrossRef] [PubMed]

8. Baade, P.D.; Meng, X.; Youl, P.H.; Aitken, J.F.; Dunn, J.; Chambers, S.K. The impact of body mass index and physical activity on mortality among patients with colorectal cancer in Queensland, Australia. Cancer Epidemiol. Biomark. Prev. 2011, 20, 1410-1420. [CrossRef] [PubMed]

9. Boyle, T.; Fritschi, L.; Platell, C.; Heyworth, J. Lifestyle factors associated with survival after colorectal cancer diagnosis. Br. J. Cancer 2013, 109, 814-822. [CrossRef] [PubMed]

10. Campbell, P.T.; Patel, A.V.; Newton, C.C.; Jacobs, E.J.; Gapstur, S.M. Associations of recreational physical activity and leisure time spent sitting with colorectal cancer survival. J. Clin. Oncol. 2013, 31, 876-885. [CrossRef] [PubMed]

11. Hardikar, S.; Newcomb, P.A.; Campbell, P.T.; Win, A.K.; Lindor, N.M.; Buchanan, D.D.; Makar, K.W.; Jenkins, M.A.; Potter, J.D.; Phipps, A.I. Prediagnostic Physical Activity and Colorectal Cancer Survival: Overall and Stratified by Tumor Characteristics. Cancer Epidemiol. Biomark. Prev. 2015, 24, 1130-1137. [CrossRef]

12. Haydon, A.M.; Macinnis, R.J.; English, D.R.; Giles, G.G. Effect of physical activity and body size on survival after diagnosis with colorectal cancer. Gut 2006, 55, 62-67. [CrossRef] [PubMed]

13. Jayasekara, H.; English, D.R.; Haydon, A.; Hodge, A.M.; Lynch, B.M.; Rosty, C.; Williamson, E.J.; Clendenning, M.; Southey, M.C.; Jenkins, M.A.; et al. Associations of alcohol intake, smoking, physical activity and obesity with survival following colorectal cancer diagnosis by stage, anatomic site and tumor molecular subtype. Int. J. Cancer 2018, 142, 238-250. [CrossRef]

14. Kuiper, J.G.; Phipps, A.I.; Neuhouser, M.L.; Chlebowski, R.T.; Thomson, C.A.; Irwin, M.L.; Lane, D.S.; Wactawski-Wende, J.; Hou, L.; Jackson, R.D.; et al. Recreational physical activity, body mass index, and survival in women with colorectal cancer. Cancer Causes Control 2012, 23, 1939-1948. [CrossRef] [PubMed]

15. Meyerhardt, J.A.; Giovannucci, E.L.; Holmes, M.D.; Chan, A.T.; Chan, J.A.; Colditz, G.A.; Fuchs, C.S. Physical activity and survival after colorectal cancer diagnosis. J. Clin. Oncol. 2006, 24, 3527-3534. [CrossRef] [PubMed]

16. Meyerhardt, J.A.; Giovannucci, E.L.; Ogino, S.; Kirkner, G.J.; Chan, A.T.; Willett, W.; Fuchs, C.S. Physical activity and male colorectal cancer survival. Arch. Intern. Med. 2009, 169, 2102-2108. [CrossRef]

17. Walter, V.; Jansen, L.; Knebel, P.; Chang-Claude, J.; Hoffmeister, M.; Brenner, H. Physical activity and survival of colorectal cancer patients: Population-based study from Germany. Int. J.Cancer 2017, 140, 1985-1997. [CrossRef]

18. Yamauchi, M.; Lochhead, P.; Imamura, Y.; Kuchiba, A.; Liao, X.; Qian, Z.R.; Nishihara, R.; Morikawa, T.; Shima, K.; Wu, K.; et al. Physical activity, tumor PTGS2 expression, and survival in patients with colorectal cancer. Cancer Epidemiol. Biomark. Prev. 2013, 22, 1142-1152. [CrossRef]

19. Guthold, R.; Stevens, G.A.; Riley, L.M.; Bull, F.C. Worldwide trends in insufficient physical activity from 2001 to 2016 : A pooled analysis of 358 population-based surveys with 1.9 million participants. Lancet Glob. Health 2018, 6, e1077-e1086. [CrossRef]

20. Cheol Seong, S.; Kim, Y.Y.; Khang, Y.H.; Heon Park, J.; Kang, H.J.; Lee, H.; Do, C.H.; Song, J.S.; Hyon Bang, J.; Ha, S.; et al. Data Resource Profile: The National Health Information Database of the National Health Insurance Service in South Korea. Int. J. Epidemiol. 2017, 46, 799-800. [CrossRef]

21. Jang, D.; Choe, S.; Park, J.W.; Jeong, S.-Y.; Shin, A. Smoking status before and after colorectal cancer diagnosis and mortality in Korean men: A population-based cohort study. Cancer Med. 2020, 9, 9641-9648. [CrossRef] [PubMed]

22. World Health Organization. The Asia-Pacific Perspective: Redefining Obesity and Its Treatment; Health Communications: Sydney, NSW, Australia, 2000; pp. 18-19.

23. Dietary Guidelines Advisory Committee. Dietary Guidelines for Americans, 2015-2020, 8th ed.; United States Department of Health and Human Services, United States Department of Agriculture: Washington, DC, USA, 2015; p. 13. 
24. Quan, H.; Sundararajan, V.; Halfon, P.; Fong, A.; Burnand, B.; Luthi, J.C.; Saunders, L.D.; Beck, C.A.; Feasby, T.E.; Ghali, W.A. Coding algorithms for defining comorbidities in ICD-9-CM and ICD-10 administrative data. Med. Care 2005, 43, 1130-1139. [CrossRef] [PubMed]

25. Collett, D. Modelling Survival Data in Medical Research, 3rd ed.; Chapman \& Hall/CRC: Philadelphia, PA, USA, $2014 ;$ pp. 161-163.

26. Hojman, P.; Gehl, J.; Christensen, J.F.; Pedersen, B.K. Molecular Mechanisms Linking Exercise to Cancer Prevention and Treatment. Cell Metab. 2018, 27, 10-21. [CrossRef] [PubMed]

27. Francipane, M.G.; Lagasse, E. mTOR pathway in colorectal cancer: An update. Oncotarget 2014, 5, 49-66. [CrossRef] [PubMed]

28. Thompson, H.J.; Jiang, W.; Zhu, Z. Candidate mechanisms accounting for effects of physical activity on breast carcinogenesis. IUBMB Life 2009, 61, 895-901. [CrossRef]

29. Dieli-Conwright, C.M.; Parmentier, J.H.; Sami, N.; Lee, K.; Spicer, D.; Mack, W.J.; Sattler, F.; Mittelman, S.D. Adipose tissue inflammation in breast cancer survivors: Effects of a 16-week combined aerobic and resistance exercise training intervention. Breast Cancer Res. Treat. 2018, 168, 147-157. [CrossRef]

30. Pedersen, L.; Idorn, M.; Olofsson, G.H.; Lauenborg, B.; Nookaew, I.; Hansen, R.H.; Johannesen, H.H.; Becker, J.C.; Pedersen, K.S.; Dethlefsen, C.; et al. Voluntary Running Suppresses Tumor Growth through Epinephrine- and IL-6-Dependent NK Cell Mobilization and Redistribution. Cell Metab. 2016, 23, 554-562. [CrossRef]

31. Courneya, K.S.; Mackey, J.R.; Bell, G.J.; Jones, L.W.; Field, C.J.; Fairey, A.S. Randomized controlled trial of exercise training in postmenopausal breast cancer survivors: Cardiopulmonary and quality of life out-comes. J. Clin. Oncol. 2003, 21, 1660-1668. [CrossRef]

32. Mock, V.; Dow, K.H.; Meares, C.J.; Grimm, P.M.; Dienemann, J.A.; Haisfield-Wolfe, M.E.; Quitasol, W.; Mitchell, S.; Chakravarthy, A.; Gage, I. Effects of exercise on fatigue, physical functioning, and emotional distress during radiation therapy for breast cancer. Oncol. Nurs. Forum. 1997, 24, 991-1000.

33. Mohamady, H.M.; Elsisi, H.F.; Aneis, Y.M. Impact of moderate intensity aerobic exercise on chemotherapy-induced anemia in elderly women with breast cancer: A randomized controlled clinical trial. J. Adv. Res. 2017, 8, 7-12. [CrossRef]

34. Chen, H.M.; Tsai, C.M.; Wu, Y.C.; Lin, K.C.; Lin, C.C. Randomised controlled trial on the effectiveness of home-based walking exercise on anxiety, depression and cancer-related symptoms in patients with lung cancer. Br. J. Cancer 2015, 112, 438-445. [CrossRef] [PubMed]

35. Wei, E.K.; Giovannucci, E.; Wu, K.; Rosner, B.; Fuchs, C.S.; Willett, W.C.; Colditz, G.A. Comparison of risk factors for colon and rectal cancer. Int. J. Cancer 2004, 108, 433-442. [CrossRef]

36. Tamas, K.; Walenkamp, A.M.; de Vries, E.G.; van Vugt, M.A.; Beets-Tan, R.G.; van Etten, B.; de Groot, D.J.; Hospers, G.A. Rectal and colon cancer: Not just a different anatomic site. Cancer Treat. Rev. 2015, 41, 671-679. [CrossRef] [PubMed]

37. Skelly, A.C. Probability, proof, and clinical significance. Evid. Based Spine Care. J. 2011, 2, 9-11. [CrossRef]

38. Adamsen, L.; Midtgaard, J.; Rorth, M.; Borregaard, N.; Andersen, C.; Quist, M.; Moller, T.; Zacho, M.; Madsen, J.K.; Knutsen, L. Feasibility, physical capacity, and health benefits of a multidimensional exercise program for cancer patients undergoing chemotherapy. Support. Care Cancer 2003, 11, 707-716. [CrossRef]

39. Courneya, K.S.; Friedenreich, C.M. Physical exercise and quality of life following cancer diagnosis: A literature review. Ann. Behav. Med. 1999, 21, 171-179. [CrossRef]

40. Schwartz, A.L. Physical activity after a cancer diagnosis: Psychosocial outcomes. Cancer Investig. 2004, 22, 82-92. [CrossRef]

41. Nocon, M.; Hiemann, T.; Muller-Riemenschneider, F.; Thalau, F.; Roll, S.; Willich, S.N. Association of physical activity with all-cause and cardiovascular mortality: A systematic review and meta-analysis. Eur. J. Cardiovasc. Prev. Rehabil. 2008, 15, 239-246. [CrossRef]

42. Zaorsky, N.G.; Churilla, T.M.; Egleston, B.L.; Fisher, S.G.; Ridge, J.A.; Horwitz, E.M.; Meyer, J.E. Causes of death among cancer patients. Ann. Oncol. 2017, 28, 400-407. [CrossRef] [PubMed]

43. Wu, W.; Guo, F.; Ye, J.; Li, Y.; Shi, D.; Fang, D.; Guo, J.; Li, L. Pre- and post-diagnosis physical activity is associated with survival benefits of colorectal cancer patients: A systematic review and meta-analysis. On-Cotarget 2016, 7, 52095-52103. [CrossRef] [PubMed]

44. Ministry of Health and Welfare (KR); National Cancer Center (KR). Cancer Facts E Figures 2017 in the Republic of Korea; Ministry of Health and Welfare: Sejong, Korea, 2017. 